\title{
Effects of institutionalizing limited obstetric ultrasound services on utilization of maternal and neonatal health services: a pre-post study
}

Hailemariam Segni Abawollo ( $\sim$ hailemariam_segni@et.jsi.com )

JSI Research \& Training Institute Inc

Mesele Damte Argaw

JSI Research \& Training Institute Inc

Zergu Tafesse Tsegaye

JSI Research \& Training Institute Inc

Ismael Ali Beshir

JSI Research \& Training Institute Inc

Asfaw Adugna Guteta

JSI Research \& Training Institute Inc

Atrie Fekadu Heyi

JSI Research \& Training Institute Inc

Birhan Tenaw Mengesha

JSI Research \& Training Institute Inc

Tsega Teferi Mamo

JSI Research \& Training Institute Inc

Zenawork Kassahun Gebremedhin

JSI Research \& Training Institute Inc

Heran Demise Damte

JSI Research \& Training Institute Inc

Mengistu Asnake Kibret

Pathfinder International

Binyam Fekadu Desta

JSI Research \& Training Institute Inc

\section{Research Article}

Keywords: Ultrasound, Task sharing, Task shifting, Point of care ultrasound, Obstetric ultrasound

Posted Date: January 27th, 2022

DOI: https://doi.org/10.21203/rs.3.rs-1297883/v1 
License: (c) (i) This work is licensed under a Creative Commons Attribution 4.0 International License. Read Full License 


\section{Abstract \\ Background}

A minimum of one ultrasound scan is recommended for all pregnant women before the 24th week of gestation. In Ethiopia, there is a shortage of skilled manpower to provide these services. Currently, trained mid-level providers are providing the services at the primary healthcare level.

\section{Methods}

A pre and post intervention observational study was conducted to understand maternal health service utilization rates before and after institutionalizing Vscan access limited obstetric ultrasound services between 2017 and 2020.

\section{Results}

The observed monthly increase on the mean rank of first ANC visits after the introduction of Vscan limited obstetric ultrasound services shows a statistically significant difference at KW-ANOVA H (3) $=17.09, P=0.001$. The mean rank of fourth ANC utilization increment shows statistically significant difference at KW- ANOVA H (3) $=16.24, P=0.001$. The observed mean rank in skilled birth attendance shows a statistically significant positive difference using KW-ANOVA $H(3)=23.6, P<0.001$. The mean rank of increased utilization in postnatal care shows a statistically significant difference using KWANOVA H (3) $=17.79, \mathrm{P}<0.001$.

\section{Conclusion}

The introduction of limited obstetric ultrasound services by trained mid-level providers at primary healthcare levels was found to have improved the utilization of antenatal care, skilled birth attendance, and postnatal care services. It is recommended that limited obstetric ultrasound services be scaled up, and a further comparative study between facilities with and without ultrasound services be conducted to assess the effect of the introduction of the services on maternal and perinatal outcomes.

\section{Background}

Globally, 295,000 women died during and following pregnancy and childbirth in 2017. Most of these deaths occurred in low-resource settings [1]. The World Health Organization (WHO) had estimated a total death of 2.5 million children within the first month of their life, in 2018 [2]. Furthermore, 2.6 million babies are stillborn, with half of these deaths occurring at home [3]. 
Ethiopia is a low-income country with high incidences of maternal and neonatal mortalities. Over the past couple of decades, the Government of Ethiopia, its citizens, and development partners have successfully implemented most global and national commitments. During the implementation of health sector development programs spanning 20 years, the country has heavily invested its resources into improving maternal, neonatal and child health outcomes [4]. Despite this, the country has gained minimal results in the reduction of maternal and neonatal mortalities [5]. Although maternal mortality has declined from 708 per 100,000 live births in 1990 to 497 per 100,000 live births in 2013, the country has failed to achieve the millennium development goals (MDG) [6]. Similarly, the decline in neonatal mortality has been slow, from 63 per 1,000 live births in 1990 to 28 per 1,000 live births in 2015 [7]. Furthermore, the latest Ethiopian mini-demographic and health survey report documented a high neonatal mortality rate of 33 per 1,000 live births [8].

The WHO aims for a world where every pregnant woman and newborn receives quality care throughout pregnancy, childbirth, and postnatal periods [9]. To meet the sustainable development goals (SDGs), Ethiopia has developed its second five-year health sector transformation plan (HSTP), from 2020/21 to $2024 / 25$. One of the strategic objectives of the HSTP is reducing maternal mortality from 401 per 100,000 live births to 279 per 100,000 live births, and neonatal mortality from 33 per 1,000 live births to 21 per 1,000 live births [10].

Most maternal and perinatal deaths are preventable with the institution of high impact and cost-effective interventions during pregnancy, labor, delivery, and postpartum periods. One of these interventions is the delivery of quality antenatal care (ANC) services. In 2016, the WHO recommended a minimum of eight ANC contact visits for expectant women, with specified evidence-based and beneficial interventions being administered during those contacts. One of the recommendations is mandatory ultrasound (U/S) scanning of all pregnant women at least once before the 24th week of gestation by skilled providers [9].

The attainment of the Ministry of Health $(\mathrm{MoH})$ of Ethiopia's vision "to see productive and prosperous citizens" is challenged with extreme shortage of human resources $[3,11]$. During the year 2020, there were 95 radiologists and 462 obstetricians and gynecologists available to provide obstetric ultrasound services in the country, which has population of over 110 million. Optimizing the capacity of existing human resources, and distribution of tasks and responsibilities among various health professionals will improve access to, and quality and equity of health services [12].

The United States Agency for International Development (USAID) funds the USAID Transform: Primary Health Care project (2017- 2022) to support the $\mathrm{MoH}$ in line with its long-term goal of preventing maternal and child deaths (PCMD) [13].

To improve access to, and quality and equity of basic maternal and neonatal health services, the project, in collaboration with its technology partner General Electric Co. introduced Vscan access-a small portable ultrasound devise, for obstetric scanning by trained mid-level providers in 100 health centers [14]. The project strategizes to increase skilled birth attendance (SBA), introduce point of care ultrasound scanning services during ANC, and improve the proper management of complications of pregnancies in 
referral health facilities all of which will contribute to improvements in maternal, fetal, and neonatal positive health outcomes $[13,15]$.

Studies have documented improvements in maternal and neonatal health service utilization and favorable pregnancy outcomes for both mother and baby, as a result of availing obstetric point of care ultrasound services and improved quality of services in remote places around the world [16-27]. In addition, during the second HSTP, the $\mathrm{MoH}$ of Ethiopia has a plan to introduce ultrasound services in about one thousand health centers. This study aims to assess the effects of institutionalizing Vscan access limited obstetric ultrasound services on ANC, skilled delivery, and postnatal care (PNC) service utilization in Ethiopia. To the authors' knowledge, this study is of the first of its kind in the country and will be used to guide policy on the area.

\section{Methods}

\section{Design, period, and setting}

A pre and post intervention observational study was conducted to understand maternal and neonatal health service utilization rates before and after institutionalizing Vscan access limited obstetric ultrasound services between 2017 and 2020. The study was conducted in Amhara, Oromia, and Southern Nations, Nationalities and Peoples' (SNNP) Regions. These regions were selected due to the presence of Vscan limited obstetric ultrasound services in selected health centers, for over two years. A health center is a public health facility serving 25,000 inhabitants within the primary healthcare system of Ethiopia, which has a mandate to provide promotive, preventive, curative, and rehabilitative outpatient care including basic laboratory and pharmacy services with a capacity for 10 beds for emergency and delivery services [28].

\section{Intervention}

In October 2018, the USAID Transform: Primary Health Care project facilitated a ten-day classroom didactic course and practical, hands-on Vscan ultrasound machine operation demonstrations, followed by three sessions of two-day-long onsite and off-site mentoring for each trainee, for a total of 3 months. The contents of the training curriculum consisted of normal pregnancy, ultrasound basics, first trimester pregnancy, fetal dating, biometry measurements, second trimester pregnancy, third trimester pregnancy, and complications. The training was facilitated by experienced obstetrician and gynecologist, a radiologist, and a GE Healthcare technical rxpert using the Vscan access ultrasound machines.

The course delivery modalities included an interactive lecture delivered by trainers, facilitated discussions on selected cases, management algorithms, and ultrasound images, and report presentations by trainees. After each of the classroom sessions, a practical demonstration on pregnant women by trainers was followed by hands-on supervised exercise among trainees. The practical exercises continued for three months, within the regular work assignment places of each of the trainees. The project supported each facility with provisions of a startup ultrasound gel, recording books, and reporting forms. Trainees stored 
the ultrasound images and maternal biodata within the ultrasound machine. The information was used to facilitate experience sharing and face-to-face mentoring sessions. During the mentoring sessions, trainers assess image quality and determine the consistency of the trainees' reports. Then, hands-on supervised scanning sessions were arranged for trainees with identified gaps in skills of scanning and report writing. Furthermore, trainees were encouraged to share their images via a Telegram group phone application and received real time feedback from trainers. At the end of the three-month-long mentoring, (end of December 2018), trainees were certified after the minimum requirements in both knowledge and skills were met. The district health offices disseminated the introduction of the limited obstetric ultrasound services using different community platforms. The number of mothers that received ultrasound scanning services for the first, second, and third or more times within the two years after the introduction of the services were $10,186,2,974$, and 1,509 respectively.

\section{Sample size and sampling}

The Vscan limited obstetric ultrasound services were institutionalized in one hundred targeted health centers. The sample size was determined using the rule of thumb recommendation of The Aga Khan Foundation (1997) [29]. To conduct the service quality assessment -based on the size of targeted population -the foundation suggests four sample size approaches: (1) if the number of facilities is very large $(500-1,000)$, take a ten percent sample, (2) if it is medium size (100 -500), take a $15-20$ percent sample, (3) if it is small (50-100) take a 20 - 30 percent sample, and (4) if it is very small (less than 50), take a $30-50$ percent sample. Therefore, for this study, 30 health centers were sampled $(30 \%$ of the 100 health centers). The three regions were selected based on the accessibility and functionality of the ultrasound services during the time of data collection. Finally, a simple, random sampling technique was applied to identify individual facilities.

\section{Data collection}

Three supervisors and thirty data collectors who are health science professionals were recruited from the targeted three regions. A two-day training on the objectives of the study, data collection techniques, ethical principles, and field pretesting was carried out. The data were extracted from a routine health information management system (HMIS) database using a pre-tested tool. To ensure the quality of data, three trained supervisors with master's degrees in public health were deployed in the field and provided close technical support with feedback given daily to the data collectors. The supervisors were responsible for checking and rechecking the collected data for completeness and consistencies.

The dependent variables were all pregnant women that attended ANC (ANC1 and ANC4 visits per month), gave birth with the assistance of skilled birth attendants, and had utilized PNC services.

The independent variables were years of services.

\section{Data analysis}

The data were entered and cleaned using Microsoft Excel 2016 then were exported to SPSS V25 for descriptive and inferential analysis. The effects of institutionalizing Vscan limited obstetric ultrasound 
services were determined using 1,440 data collected from the 30 health centers. The results of the statistical tests were presented using tables and graphs. To analyze $F$ tests (one-way analyses of variance, ANOVA), the data violated the assumption of homogeneity of variances of a parametric test using Shapiro-Wilk test of normality $\mathrm{P}<0.05$ (Additional file 1). Hence, an equivalent non-parametric test called The Kruskal-Wallis $\mathrm{H}$ test or a 'one-way ANOVA on ranks' was employed to determine statistically significant differences between four groups of independent variables, years of services. The statistical differences were claimed at $P<0.05$. However, the investigators maintained and ensured the following assumption of Kruskal-Wallis $\mathrm{H}$ tests: (1) the dependent variables (ANC, SBA, and PNC) are interval data, (2) the independent variable has four categories, (3) there were no relationship between observations in each group, and (4) the distribution of scores in each group were not identical [30]. Finally, a statistical analysis was employed to compare data twenty-four months (2017 and 2018) preceding the introduction of Vscan limited obstetric ultrasound services and twenty-four months (2019 and 2020) following the intervention. The mean rank monthly first ANC, fourth ANC, SBA, and PNC were compared before and after ultrasound services were initiated using a nonparametric test called Kruskal-Wallis $\mathrm{H}$ test.

\section{Ethical considerations}

Ethical clearance was granted from the John Snow, Inc., Institutional Review Board (IRB) -IRB reference number IRB\#20-26E. Informed individual written consent was obtained from each facility manager. The investigators maintained national and international ethical principles including ensuring the anonymity and confidentiality of research participant and collected data throughout the research process. Data were abstracted from a routine HMIS database. In addition, no personal identifiers were captured.

\section{Results}

\section{Description of the study population}

Characteristics of the study area and population categorized by region and service years are presented in Table 1. The majority (13/30) of the health centers were enrolled from within the Oromia Region. On average, each health center is located 58.6 kilometers away from a referral receiving hospital. At the endpoint, there were about 1.19 million people living within the study areas. Of these, the estimated number of pregnant women eligible for maternal and neonatal health services for the year 2020 were 40,506 (3.4\%) (Table 1). 
Table 1

Characteristics of the study area and population, USAID Transform: Primary health Care project intervention sites, Ethiopia, 2017- 2020.

\begin{tabular}{|lllll|}
\hline Characteristics & Amhara & Oromia & SNNP & Total \\
\hline Number of health centers & 9 & 13 & 8 & 30 \\
\hline $\begin{array}{l}\text { Average distance from a referral receiving facility in } \\
\text { kilometers }\end{array}$ & 59.5 & 70.4 & 38.4 & 58.6 \\
\hline Population & & & & \\
\hline 2017 & 329,038 & 529,008 & 242,815 & $1,100,861$ \\
\hline 2018 & 337,822 & 543,129 & 249,298 & $1,130,249$ \\
\hline 2019 & 346,841 & 557,628 & 255,953 & $1,160,422$ \\
\hline 2020 & 356,100 & 572,513 & 262,785 & $1,191,398$ \\
\hline Eligible women & & & & \\
\hline 2017 & 11,873 & 19,270 & 8,858 & 40,001 \\
\hline 2018 & 11,949 & 19,333 & 8,884 & 40,166 \\
\hline 2019 & 12,028 & 19,398 & 8,909 & 40,335 \\
\hline 2020 & 12,106 & 19,464 & 8,936 & 40,506 \\
\hline
\end{tabular}

\section{Maternal and neonatal health service utilization}

A Kruskal-Wallis test was conducted to determine if there were differences in first ANC, fourth ANC, SBA, and PNC service scores between groups that differed in service years. The adjusted p-values are presented.

Figure 1 and Table 2 depict the results of a retrospective assessment of maternal and neonatal health service beneficiaries and coverages with a category of prior to and post the introduction of ultrasound services in the thirty health centers.

The coverages of service utilization for first ANC were $43.6 \%$ and $72.9 \%$ for the years 2017 and 2020 , respectively. In addition, the mean numbers of the first ANC visits were $765( \pm S D)$ and $1126.9( \pm S D)$ for equal reporting periods of pre- and post-ultrasound introduction in the thirty selected health centers. The observed monthly increase on mean rank of first ANC visits after introduction of Vscan limited obstetric ultrasound service shows a statistically significant difference at KW-ANOVA H (3) $=17.09, \mathrm{P}=0.001$.

The average fourth ANC visit coverages were $43.8 \%$ and $68.3 \%$ for the years 2017 and 2020, respectively. Similarly, the mean numbers of fourth ANC visits were $534( \pm S D)$ and $777.5( \pm S D)$ during the pre- and post-ultrasound introduction periods, respectively. The mean rank of fourth ANC increased utilization shows statistically significant difference at KW- ANOVA H (3) $=16.24, P=0.001$. 
The average SBA service utilization coverages were $40.2 \%$ and $75.6 \%$ for the years 2017 and 2020 respectively. The mean numbers of SBA in the thirty health centers were $487.9( \pm S D)$ and $761.5( \pm S D)$ twenty-four months pre- and twenty-four months post-ultrasound introduction, respectively. The observed mean rank SBA has shown a statistically significant positive difference using KW-ANOVA H (3) $=23.6$, $\mathrm{P}<0.001$.

The average PNC service coverages were $44.4 \%$ and $75.4 \%$ for the years 2017 and 2020, respectively. The mean numbers of PNC service utilization for 48 months in the 30 health centers were $511.8( \pm S D)$ and $790.1( \pm S D)$ during prior to and after the introduction of ultrasound services, respectively. The mean rank of PNC service utilization increase has shown a statistically significant difference using KW-ANOVA H (3) $=17.79, \mathrm{P}<0.001$. 
Table 2

Number of monthly ANC, SBA, and PNC services utilization in thirty health centers pr-e and postultrasound introduction in Ethiopia, 2017-2020.

\begin{tabular}{|c|c|c|c|c|c|c|}
\hline Measurements & Time & $\begin{array}{l}\text { Facility- } \\
\text { months }\end{array}$ & $\begin{array}{l}\text { Mean } \\
\text { (SD) }\end{array}$ & Median & $\begin{array}{l}\text { Min- } \\
\text { Max }\end{array}$ & $95 \% \mathrm{Cl}$ \\
\hline \multirow[t]{6}{*}{$\begin{array}{l}\text { Number of first } \\
\text { ANC visits }\end{array}$} & 2017 & 720 & $\begin{array}{l}705.7 \\
(378.8)\end{array}$ & 636.5 & $\begin{array}{l}136- \\
1859\end{array}$ & $\begin{array}{l}564.3- \\
847.2\end{array}$ \\
\hline & 2018 & 720 & $\begin{array}{l}824.3 \\
(512.2)\end{array}$ & 625.0 & $\begin{array}{l}251- \\
2253\end{array}$ & $\begin{array}{l}633.1- \\
1015.6\end{array}$ \\
\hline & $\begin{array}{l}\text { Pre-ultrasound } \\
\text { introduction }\end{array}$ & 1440 & $\begin{array}{l}765 \\
(450.6)\end{array}$ & 625.0 & $\begin{array}{l}136- \\
2253\end{array}$ & $\begin{array}{l}648.6- \\
881.4\end{array}$ \\
\hline & 2019 & 720 & $\begin{array}{l}1130.3 \\
(617.6)\end{array}$ & 905.5 & $\begin{array}{l}254- \\
2916\end{array}$ & $\begin{array}{l}899.6- \\
1360.9\end{array}$ \\
\hline & 2020 & 720 & $\begin{array}{l}1123.6 \\
(625.7)\end{array}$ & 905.5 & $\begin{array}{l}254- \\
2916\end{array}$ & $\begin{array}{l}889.9- \\
1357.3\end{array}$ \\
\hline & $\begin{array}{l}\text { Post-ultrasound } \\
\text { introduction }\end{array}$ & 1440 & $\begin{array}{l}1126.9 \\
(616.5)\end{array}$ & 905.5 & $\begin{array}{l}254- \\
2916\end{array}$ & $\begin{array}{l}967.7- \\
1286.2\end{array}$ \\
\hline \multirow[t]{6}{*}{$\begin{array}{l}\text { Number of fourth } \\
\text { ANC visits }\end{array}$} & 2017 & 720 & $\begin{array}{l}475.7 \\
(243.8)\end{array}$ & 454.5 & $\begin{array}{l}126- \\
964\end{array}$ & $\begin{array}{l}384.7- \\
566.8\end{array}$ \\
\hline & 2018 & 720 & $\begin{array}{l}592.3 \\
(409.4)\end{array}$ & 455.5 & $\begin{array}{l}218- \\
1955\end{array}$ & $\begin{array}{l}439.5- \\
745.2\end{array}$ \\
\hline & $\begin{array}{l}\text { Pre-ultrasound } \\
\text { introduction }\end{array}$ & 1440 & $\begin{array}{l}534 \\
(339.2)\end{array}$ & 454.5 & $\begin{array}{l}126- \\
1955\end{array}$ & $\begin{array}{l}446.4- \\
621.6\end{array}$ \\
\hline & 2019 & 720 & $\begin{array}{l}802.9 \\
(378.5)\end{array}$ & 754.0 & $\begin{array}{l}177- \\
2007\end{array}$ & $\begin{array}{l}661.6- \\
944.3\end{array}$ \\
\hline & 2020 & 720 & $\begin{array}{l}752.1 \\
(431.9)\end{array}$ & 665.5 & $\begin{array}{l}148- \\
1989\end{array}$ & $\begin{array}{l}590.8- \\
913.4\end{array}$ \\
\hline & $\begin{array}{l}\text { Post-ultrasound } \\
\text { introduction }\end{array}$ & 1440 & $\begin{array}{l}777.5 \\
(403.4)\end{array}$ & 715.0 & $\begin{array}{l}148- \\
2007\end{array}$ & $\begin{array}{l}673.3- \\
881.7\end{array}$ \\
\hline \multirow[t]{5}{*}{ Number of SBA } & 2017 & 720 & $\begin{array}{l}423.7 \\
(224.0)\end{array}$ & 377.5 & $\begin{array}{l}116- \\
964\end{array}$ & $\begin{array}{l}340.0- \\
507.4\end{array}$ \\
\hline & 2018 & 720 & $\begin{array}{l}552.0 \\
(384.8)\end{array}$ & 437.0 & $\begin{array}{l}218- \\
1756\end{array}$ & $\begin{array}{l}408.3- \\
695.7\end{array}$ \\
\hline & $\begin{array}{l}\text { Pre-ultrasound } \\
\text { introduction }\end{array}$ & 1440 & $\begin{array}{l}487.9 \\
(318.8)\end{array}$ & 393.5 & $\begin{array}{l}116- \\
1756\end{array}$ & $\begin{array}{l}405.5- \\
570.2\end{array}$ \\
\hline & 2019 & 720 & $\begin{array}{l}747.6 \\
(320.8)\end{array}$ & 679.5 & $\begin{array}{l}232- \\
1810\end{array}$ & $\begin{array}{l}627.8- \\
867.4\end{array}$ \\
\hline & 2020 & 720 & $\begin{array}{l}775.4 \\
(455.8)\end{array}$ & 677.5 & $\begin{array}{l}252- \\
2427\end{array}$ & $\begin{array}{l}605.2- \\
945.7\end{array}$ \\
\hline
\end{tabular}




\begin{tabular}{|c|c|c|c|c|c|c|}
\hline Measurements & Time & $\begin{array}{l}\text { Facility- } \\
\text { months }\end{array}$ & $\begin{array}{l}\text { Mean } \\
\text { (SD) }\end{array}$ & Median & $\begin{array}{l}\text { Min- } \\
\text { Max }\end{array}$ & $95 \% \mathrm{Cl}$ \\
\hline & $\begin{array}{l}\text { Post-ultrasound } \\
\text { introduction }\end{array}$ & 1440 & $\begin{array}{l}761.5 \\
(391.0)\end{array}$ & 679.5 & $\begin{array}{l}232- \\
2427\end{array}$ & $\begin{array}{l}660.4- \\
862.5\end{array}$ \\
\hline \multirow[t]{6}{*}{$\begin{array}{l}\text { Number of PNC } \\
\text { visits }\end{array}$} & 2017 & 720 & $\begin{array}{l}464.3 \\
(248.9)\end{array}$ & 434.0 & $\begin{array}{l}99- \\
983\end{array}$ & $\begin{array}{l}371.3- \\
557.3\end{array}$ \\
\hline & 2018 & 720 & $\begin{array}{l}559.4 \\
(410.4)\end{array}$ & 391.5 & $\begin{array}{l}123- \\
1756\end{array}$ & $\begin{array}{l}406.2- \\
712.7\end{array}$ \\
\hline & $\begin{array}{l}\text { Pre-ultrasound } \\
\text { introduction }\end{array}$ & 1440 & $\begin{array}{l}511.8 \\
(339.9)\end{array}$ & 398.0 & $\begin{array}{l}99- \\
1756\end{array}$ & $\begin{array}{l}424.0- \\
599.6\end{array}$ \\
\hline & 2019 & 720 & $\begin{array}{l}774.6 \\
(454.6)\end{array}$ & 652.0 & $\begin{array}{l}201- \\
2339\end{array}$ & $\begin{array}{l}604.8- \\
944.3\end{array}$ \\
\hline & 2020 & 720 & $\begin{array}{l}805.7 \\
(455.9)\end{array}$ & 705.5 & $\begin{array}{l}223- \\
2427\end{array}$ & $\begin{array}{l}635.5- \\
975.9\end{array}$ \\
\hline & $\begin{array}{l}\text { Post-ultrasound } \\
\text { introduction }\end{array}$ & 1440 & $\begin{array}{l}790.1 \\
(451.6)\end{array}$ & 675.0 & $\begin{array}{l}201- \\
2427\end{array}$ & $\begin{array}{l}673.5- \\
906.8\end{array}$ \\
\hline
\end{tabular}

\section{Discussion}

Maternal and neonatal health service utilization is affected by several factors including the introduction of new technologies or services which are believed to improve the quality of services provided at health facilities.

This study has shown that the introduction of limited obstetric ultrasound services by trained mid-level providers at health centers has significantly improved the utilization of first and fourth ANC services. These findings are in alignment with studies conducted elsewhere. A scoping review has shown that the introduction of a point of care ultrasound services into routine ANC resulted in higher ANC attendance [31]. A study in Uganda showed that the rate of ANC attendance was higher where portable ultrasound was advertised, and women can be motivated to attend ANC when offered the concrete incentive of seeing their baby [32]. Other studies in Uganda showed that the introduction of a low-cost antenatal ultrasound program at a healthcare clinic in rural Uganda was associated with increases in the monthly mean number of ANC visits and increases in the number of women receiving specific recommended ANC interventions [33,34]. A study in Tanzania has also shown that the introduction of routine ultrasound scanning during ANC visits significantly increased the percentage of women attending ANC clinics four times or more [35].

Similarly, the introduction of limited obstetric ultrasound services at health centers by trained mid-level providers was found to have significantly improved the utilization of SBA services at time of delivery and the utilization of PNC services after delivery. These findings are also in alignment with studies conducted in other settings. The above-mentioned study in rural Uganda showed that, following the introduction of 
ultrasound services, significant increases were seen in the number of mean monthly deliveries [34]. The study in Tanzania has also shown that the introduction of a simplified ultrasound scanning technology at the lowest levels of care has an effect of motivating women to select health facility deliveries [35]. A study conducted in Ghana showed that the use of a portable ultrasound scan during ANC increased the number of health facility deliveries [36]. Furthermore, a study in rural Eastern China has shown a statistically significant association between antenatal ultrasound scans and the uptake of cesarean section procedures [37].

\section{Limitations}

One of the regions where Vscan access limited obstetric ultrasound services were introduced (Tigray), was not included in the study as services were interrupted due to security reasons. Confounding factors cannot be fully eliminated with a study of this design.

\section{Conclusion}

Ethiopia is one of the countries in the world with low ANC, SBA, and PNC coverages. The introduction of limited obstetric ultrasound services by trained mid-level providers at health centers was found to have improved the utilization of ANC, SBA, and PNC services. Hence, it is recommended that limited obstetric ultrasound services by trained mid-level providers at health centers be scaled up. A further comparative study to assess the effects of the introduction of limited obstetric ultrasound services by trained mid-level providers in health centers on maternal and perinatal health outcomes is also recommended.

\section{Declarations}

Ethical approval and consent to participate: Ethical clearance was granted from the John Snow, Inc., Institutional Review Board (IRB), IRB reference number IRB\#20-26E. Informed individual written consent was obtained from each facility manager. The investigators maintained national and international ethical principles including ensuring anonymity and confidentiality of research participants and the collected data throughout the research process. Data were abstracted from a routine health management information system database. In addition, no personal identifiers were captured.

Consent for publication: Consent for publication is not applicable for this research.

Availability of data and materials: The datasets analyzed during the current study are available from the corresponding author upon reasonable request.

Competing interests: All the authors declare that they do not have any competing interests.

Funding: This study was fully funded by USAID as part of USAID Transform: Primary Health Care project implemented under cooperative agreement number of AID-663-A-17-00002 in Ethiopia. The funding body 
had no role in the design, data collection, analysis, interpretation, and writing stages of the study's undertaking.

Authors' contributions: HSA, MDA, ZTT, IAB and BFD were involved in the inception, concept note development, data collection, analysis, interpretation, and write up of the manuscript. AAG, AFH, BTM, TTM, and ZKG were involved during the data collection stage. HDD, MAK, and BFD validated the research findings and revised the final manuscript. All authors have read and approved to the manuscript. HSA submitted the manuscript as a corresponding author.

Acknowledgments: The authors would like to acknowledge USAID for funding the study. We are indebted to data managers, data collectors, supervisors, and health facility heads.

\section{Abbreviations}

ANC-Antenatal care, GE-General Electric, HMIS-Health Management Information System, HSTP-Health Sector Transformation Plan, IRB-Institutional Review Board, MDG-Millennium Development Goal, $\mathrm{MoH}-$ Ministry of Health, PCMD-Prevention of Child and Maternal Deaths, SBA-Skilled Birth Attendance/t, SDStandard Deviation, SDG-Sustainable Development Goal, SNNP-South Nations Nationalities and Peoples', U/S-Ultrasound, USAID-United States Agency for International Development, WHO-World Health Organization,

\section{References}

1. Trends in maternal mortality 2000 to 2017: estimates by WHO, UNICEF, UNFPA, World Bank Group and the United Nations Population Division. Geneva: World Health Organization; 2019. Licence: CC BY-NC-SA 3.0 IGO.

2. Arsenault C, Jordan K, Lee D, Dinsa G, Manzi F, Marchant T, Kruk ME. Equity in antenatal care quality: an analysis of 91 national household surveys. The Lancet Global Health. 2018 Nov 1;6(11): e118695.

3. World Health Organization. Newborns: reducing mortality. WHO, Geneva; 2019. Available from: https://www.who.int/news-room/fact-sheets/detail/newborns-reducing-mortality.

4. The Federal Democratic Republic of Ethiopia, Ministry of Health. 2015. Health Sector Transformation Plan 2015/16-2019/20. Addis Ababa, Ethiopia.

5. United Nations. Assessing Progress in Africa toward the Millennium Development Goals. MDG Report. UN, New York, 2012.

6. Tessema GA, Laurence CO, Melaku YA, Misganaw A, Woldie SA, Hiruye A, Amare AT, Lakew Y, Zeleke BM, Deribew A. Trends and causes of maternal mortality in Ethiopia during 1990-2013: findings from the Global Burden of Diseases study 2013. BMC public health. 2017 Feb 2;17(1):160. doi: 10.1186/s12889-017-4071-8. 
7. United Nations Children's Fund. Maternal and Newborn Health Disparities, Ethiopia country profiles. UNICEF, 2017.

8. Central statistics agency (CSA) [Ethiopia] and ICF. 2019. Ethiopian mini-Demographic and Health Survey (EDHS). 2019. Addis Ababa, Ethiopia, and Rockville, Maryland, USA: CSA and ICF.

9. World Health Organization. WHO recommendations on antenatal care for a positive pregnancy experience. World Health Organization; 2016.

10. The Federal Democratic Republic of Ethiopia, Ministry of Health. 2021. Health Sector Transformation Plan II, 2020/21-2024/25. Addis Ababa, Ethiopia.

11. Afriyie DO, Nyoni J, Ahmat A. The state of strategic plans for the health workforce in Africa. BMJ Glob Health 2019;4:e001115. doi:10.1136/bmjgh-2018-001115.

12. World Health Organization. WHO recommendations: optimizing health worker roles to improve access to key maternal and newborn health interventions through task shifting, optimize MNH. World Health Organization; 2012.

13. USAID Transform: Primary Health Care Project. Theory of change in practice 2017. Addis Ababa: USAID Transform: Primary Health Care; 2017.

14. GE Healthcare. Vscan Access ${ }^{\mathrm{TM}}$ Ultrasound. Assessing risk. Expanding reach. (๐ 2015 General Electric Company

15. Franklin, H.L., Mirza, W., Swanson, D.L. et al. Factors influencing referrals for ultrasound-diagnosed complications during prenatal care in five low- and middle-income countries. Reprod Health 15, 204 (2018). https://doi.org/10.1186/s12978-018-0647-8

16. Greenwold N, Wallace S, Prost A, Jauniaux E. Implementing an obstetric ultrasound training program in rural Africa. Int J Gynaecol Obstet. 2014 Mar;124(3):274-7. doi: 10.1016/j.ijgo.2013.09.018.

17. Ross AB, DeStigter KK, Rielly M, Souza S, Morey GE, Nelson M, Silfen EZ, Garra B, Matovu A, Kawooya MG. A low-cost ultrasound program leads to increased antenatal clinic visits and attended deliveries at a health care clinic in rural Uganda. PloS one. 2013;8(10).

18. Mbuyita S, Tillya R, Godfrey R, Kinyonge I, Shaban J, Mbaruku G. Effects of introducing routinely ultrasound scanning during Ante Natal Care (ANC) clinics on number of visits of ANC and facility delivery: a cohort study. Archives of Public Health. 2015 Dec;73(1):36.

19. Milart PH, Molina CA, Prieto-Egido I, Martínez-Fernández A. Use of a portable system with ultrasound and blood tests to improve prenatal controls in rural Guatemala. Reproductive health. $2016 \mathrm{Dec}$ 1;13(1):110.

20. Vinayak S, Sande J, Nisenbaum H, Nolsøe CP. Training midwives to perform basic obstetric point-ofcare ultrasound in rural areas using a tablet platform and mobile phone transmission technology $-\mathrm{A}$ WFUMB COE project. Ultrasound in medicine \& biology. 2017 Oct 1;43(10):2125-32.

21. Westerway SC. Comparing the effectiveness of training course formats for point-of-care ultrasound in the third trimester of pregnancy. Australasian Journal of Ultrasound in Medicine. 2019 Feb;22(1):45-50. 
22. Wastlund D, Moraitis AA, Dacey A, Sovio U, Wilson EC, Smith GC. Screening for breech presentation using universal late-pregnancy ultrasonography: A prospective cohort study and cost effectiveness analysis. PLoS medicine. 2019 Apr;16(4).

23. Swanson, J., Kawooya, M., Swanson, D. et al. The diagnostic impact of limited, screening obstetric ultrasound when performed by midwives in rural Uganda. J Perinatol 34, 508-512 (2014). https://doi.org/10.1038/jp.2014.54

24. Kozuki N, Mullany LC, Khatry SK, Ghimire RK, Paudel S, Blakemore K, Bird C, Tielsch JM, LeClerq SC, Katz J. Accuracy of home-based ultrasonographic diagnosis of obstetric risk factors by primary-level health workers in rural Nepal. Obstetrics and gynecology. 2016 Sep;128(3):604.

25. Cherniak W, Anguyo G, Meaney C, Kong LY, Malhame I, Pace R, Sodhi S, Silverman M. Effectiveness of advertising availability of prenatal ultrasound on uptake of antenatal care in rural Uganda: A cluster randomized trial. PloS one. 2017;12(4).

26. Keable J, Crozier K. Detection of breech presentation: Abdominal palpation and hand-held scanning by midwives. British Journal of Midwifery. 2018 Jun 2;26(6):371-6.

27. Kawooya MG, Nathan RO, Swanson J, Swanson DL, Namulema E, Ankunda R, Kirumira F, DdunguMatovu P. Impact of introducing routine antenatal ultrasound services on reproductive health indicators in Mpigi District, Central Uganda. Ultrasound quarterly. 2015 Dec 1;31(4):285-9.

28. Ethiopian Standard Agency (ESA). Health Center Requirements. Addis Ababa: Ethiopian Standard Agency; 2011.

29. The Aga Khan Foundation. Primary Care Advancement Program: assessing the quality of service. 2nd edition. Washington DC.: The Aga Khan Foundation, 1997.

30. Statistics L. Kruskal-Wallis $\mathrm{H}$ test using SPSS statistics. Statistical tutorials and software guides. 2015. Accessed from https://statistics.laerd.com/spss-tutorials/kruskal-wallis-h-test-using-spssstatistics.php

31. Mikaela Doig, Janine Dizon, Katherine Guerrero and Nayana Parange. Exploring the availability and impact of antenatal point-of-care ultrasound services in rural and remote communities: A scoping review. Austarlas J Ultrason Med. August 2019; 22 (3): 174-185.

32. Cherniak W, Anguyo G, Meaney C, Yuan Kong L, Malhame I, Pace R, et al. (2017) Effectiveness of advertising availability of prenatal ultrasound on uptake of antenatal care in rural Uganda: A cluster randomized trial. PLoS ONE 12(4): e0175440. https://doi.org/10.1371/journal. pone.0175440

33. Andrew B Ross et al. Ancillary benefits of antenatal ultrasound: an association between the introduction of a low-cost ultrasound program and an increase in the numbers of women receiving recommended antenatal treatments. BMC Pregnancy and Childbirth (2014) 14:424. DOI 10.1186/s12884-014-0424-9

34. Ross AB, De Stigter KK, Rielly M, Souza S, Morey GE, et al. (2013). A Low-Cost Ultrasound Program Leads to Increased Antenatal Clinic Visits and Attended Deliveries at a Health Care Clinic in Rural Uganda. PLoS ONE 8(10): e78450. doi:10.1371/journal. pone.0078450. 
35. Selemani Mbuyita et al. Effects of introducing routinely ultrasound scanning during Ante Natal Care (ANC) clinics on number of visits of ANC and facility delivery: a cohort study. Archives of Public Health (2015) 73:36. DOI 10.1186/s13690-015-0086-8.

36. Benjamin Amoah et al. Boosting antenatal care attendance and number of hospital deliveries among pregnant women in rural communities: a community initiative in Ghana based on mobile phones applications and portable ultrasound scans. BMC Pregnancy and Childbirth (2016) 16:141. DOI 10.1186/s12884-016-0888-x.

37. Huang et al. Utilization of antenatal ultrasound scan and implications for caesarean section: a cross sectional study in rural Eastern China. BMC Health Services Research 2012, 12:93. http://www.biomedcentral.com/1472-6963/12/93.

\section{Figures}

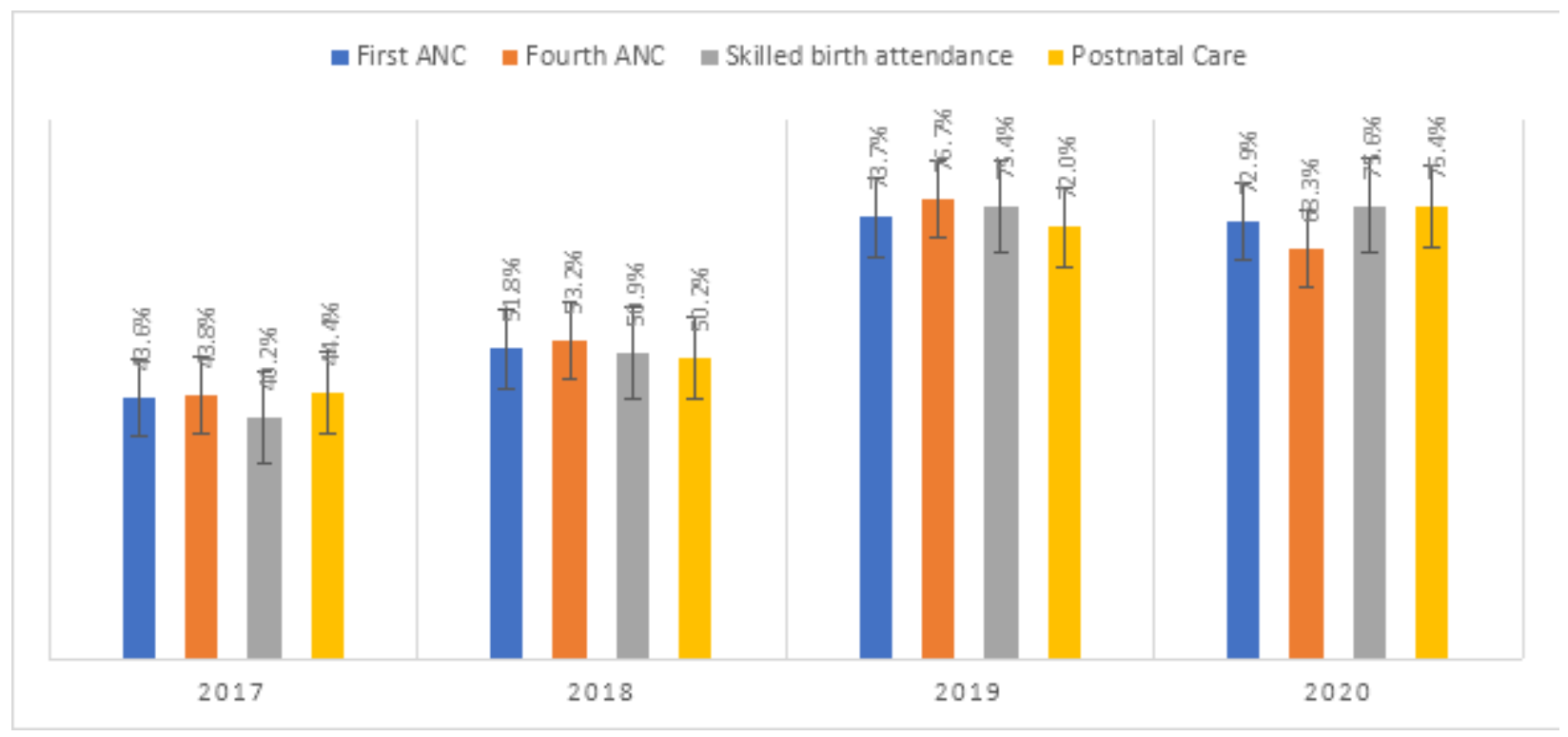

Figure 1

Bar chart showing first ANC, fourth ANC, SBA, and PNC service utilization coverages prior to and post the introduction of ultrasound services at health centers, Ethiopia, 2017-2020. 